\title{
Enhancing Students' Learning about Healthy Living through Community Participation
}

\author{
Anil Gandhi*, Hari Kumar Darnal, Ahmad Munir Qureshi, Suneet Sood, Rusli Bin Nordin \\ Clinical School Johor Bahru, Jeffrey Cheah School of Medicine and Health Sciences, Monash University, \\ Malaysia \\ Email: anil.gandhi@monash.edu
}

Received 17 August 2014; revised 16 September 2014; accepted 7 October 2014

Copyright (C) 2014 by authors and Scientific Research Publishing Inc.

This work is licensed under the Creative Commons Attribution International License (CC BY). http://creativecommons.org/licenses/by/4.0/

(c) (i) Open Access

\section{Abstract}

Introduction: The Health Enhancement Module (HEM) is taught as a core curriculum for all medical students at Monash University since 2002. In 2012 we moved the year three content of the program into a community setting, calling it the Health Enhancement Carnival (HEC). At the carnival, our undergraduates interacted with school students, their teachers, and their parents, involving them in a mix of discussions, poster presentations, and video presentations. In this paper we present our experience with the HEC. Specifically, we looked at the following two measures: how did the HEC influence the knowledge, attitude, and practice of healthy living among medical students? And, what were the learning experiences of the students during the HEC? Methods: Five themes (exercise, food, healthy sleep, workplace stress and ageing) were divided among students. They were asked to develop those themes with the help of posters, power point presentations, community talks as well as video presentations. The carnival was held in the setting of two nearby children's schools. Students were evaluated by a panel of examiners with regards to learning objectives as well as preparation and presentation. As part of evaluation, we developed 2 questionnaires. The HEP Healthy Living Questionnaire provided feedback on how the program had improved students' knowledge, attitudes, and practice of healthy living. The HEP Learning Style Questionnaire covered twelve areas, including collegiality, environment, leadership, community interaction and other facets of learning style. Analyses were performed using the IBM SPSS Statistics version 20 software in the Clinical School Johor Bahru. Results: 1) Influence of HEC on the knowledge, attitude, and practice of healthy living among medical students. From the interviews, the judges gave the students mean ratings of 4.0/5. We also received 77 out of 127 feedback questionnaires (response rate: $60.6 \%$ ) from the students. Most students (range: $49.35 \%$ to 55.84\%) were "satisfied/totally satisfied", "achieved/totally achieved", or "improved/totally improved" to 5 questions of the Healthy Living Questionnaire. Correlation coefficients between knowledge of healthy living, attitude towards healthy living, and practice of healthy living were large (exceeding 0.8) suggesting that these three measures were highly and positively inter-correlated. Most students (range: $60.28 \%$ to $71.43 \%$ ) scored "a lot/almost all", to 5 questions regarding achievement 
of learning objectives. 2) Learning experiences of the students during the HEC. Responding to the HEP Learning Style Questionnaire, most students (range: $66.24 \%$ to $85.72 \%$ ) agreed or strongly agreed that the program provided an optimal environment for learning, encouraging students to assume leadership responsibilities and promoting self-directed learning. A correlation matrix of the 12 items showed medium to large correlations between all twelve variables. Conclusions: The Health Enhancement Program (HEP) is an innovative approach that has enabled students to learn about healthy living within the context of the local community.

\section{Keywords}

Health Enhancement Program, Health Enhancement Carnival, Knowledge, Attitude and Practice, Blended Learning, Healthy Living

\section{Introduction}

The Health Enhancement Program (HEP) is taught as a core curriculum beginning from the first year of the medical curriculum (mainly theoretical) and extending into the year 3/B curriculum (with clinical contextualization) at Monash University Malaysia since 2002. Based on six topics (workplace stress, exercise as medicine, strategies to enhance sleep without drugs, food as medicine, longevity and ageing, and meaning and health), this program has the potential to significantly benefit medical student's health and wellbeing as well as to teach important clinical skills and scientific content [1].

As community attitude towards healthcare changes, the healthcare costs and adverse events spiral and there is mounting evidence that the healthcare system is steadily recognizing the importance of moving towards more holistic and wellness-based models.

The Health Enhancement Module (HEM) is taught as a core curriculum for all medical students at Monash University since 2002. The Clinical School Johor Bahru (CSJB) decided to take the issues relating to health and wellbeing as part of the HEM to the community so that everyone can benefit from it.

This Health Enhancement Carnival (HEC) is an effort to frame the core areas of the HEP, which represents a true change in how all stakeholders view and participate in propagating the benefits of healthcare, while being realistic about its challenges. Each avenue (substation) provides a perspective on different key elements of the HEM and explores the roles and reactions of participants, providers, students and their parents.

In 2012 we therefore moved the year three content of the program into a community setting, calling it the Health Enhancement Carnival (HEC). At the carnival, our undergraduates interacted with school students, their teachers, and their parents, involving them in a mix of discussions, poster presentations, and video presentations. This style of "collaborative learning" has been shown to be effective in developing critical thinking and communication skills among students.

In this paper we present our experience with the HEC. Specifically, we looked at the following two measures:

* How did the HEC influence the knowledge, attitude, and practice of healthy living among medical students?

* What were the learning experiences of the students during the HEC?

\section{Aim}

The aim of this module is to highlight the importance of life style and psychosocial factors in prevention and treatment of illnesses. These factors affect very young to elderly population in the community. Hence, this module can be better delivered at the community involving the different population groups at the community level. We found that the present mode of delivery of the module by tutorials or the student presentation neither stimulates student involvement nor generates enough enthusiasm in the students. The five main themes involving HEP module tutorials related to health and well-being include work place stress and its management, exercise as medicine, sleep as therapy, food as medicine and ageing, longevity and life-style modification. The objective of each topic as highlighted in the original Monash year 3 student document will be incorporated as guiding principles and these will be discussed with students and they will be entrusted to prepare oral/visual/power-point or video presentations and discussion in the public forum in different situations. 
The main objectives of the HEP are as follows:

1) To educate, inform, and create a better understanding of health and healthcare concepts;

2) To disseminate the importance of lifestyle and psychosocial factors in the prevention and treatment of illness;

3) To examine the evidence for the effects of these factors on health;

4) To explore the relevance of these issues to student's own self-care.

\section{Methods}

Location: In 2012, we selected a school, the Sultan Ibrahim Girls School (SIGS), in Johor Bahru for this project. In 2013, with a new batch of students, we selected a boys' school, Sekolah Menengah Kebangsaan Dato Jaafar (SDJ). During the course of our preparation we ensured that all learning objectives of the HEP were met.

The five themes (exercise, food, healthy sleep, workplace stress and ageing) were divided among the students. They were asked to prepare those topics with the help of posters, power point presentations, community talks as well as displays using videos. Our undergraduate students used these media to interact with school students, their parents, and their teachers.

As part of the program, Monash medical students had planned some activities for the staff, students and their parents. These activities intended to help to reduce workplace stress, promote healthy living by introducing some exercises and important concepts related to healthy and nutritious food. These also aimed to help in terms of longevity and aging, and touched upon some strategies to enhance sleep without any drugs.

Evaluation: The students were evaluated by a panel of judges with regards to the learning objectives as well as their preparation and the presentation. In addition, we developed two questionnaires-HEP Learning Style and Questionnaire to receive feedback from the students.

1) Influence of the carnival on knowledge, attitude, and practice: We evaluated the influence of the carnival on the knowledge, attitude, and practice of healthy living among medical students. Evaluation was conducted 1) by a report from the judges, and 2) by feedback from the students themselves.

a) The judges, who were senior teachers in the HEP, evaluated the media used by the students, and grading several parameters. The parameters included the following: quality of the booth, quality of poster display, use of audiovisual aids, and communication skills. In addition, all media were specifically evaluated with reference to the learning outcomes on pre-defined criteria. To evaluate the students, the judges conducted a question-answer session, trying to determine if the students achieved the intended learning outcomes. Depending on the station, there were either eight or nine measures per group. Each group was evaluated by two independent judges.

b) In addition, we gauged the impressions of the students themselves regarding their own attitudinal changes, using a 5-point Likert Scale to measure their responses.

2) Understanding learning experiences: To understand the learning experiences of the students during the HEC, we asked the students to fill 5-point Likert scale proforma. The questions covered the following twelve areas: collegiality [2] [3], safe and non-judgmental environment [4], participation in community education [5], assumption of leadership responsibilities [6], interaction with the community [7]-[9], participation in the sessions [10], focusing without imposing or being directive [11], responsibility for identifying learning objectives [12], post-session self-directed learning [3], prompt feedback regarding student performance [6], learning in the community [2] [13] [14], and whether the HEP was a success [15].

Statistical analysis: After data cleaning, all variables were checked for normality distribution using the stemand-leaf plot, the Kolmogirov-Smirnov Test, and the Shapiro Wilks Test. For normally distributed data, we performed simple parametric univariate and bivariate analyses; for non-normally distributed data, we performed the non-parametric equivalents. All analyses were performed using the IBM SPSS Statistics version 20 software in the Clinical School Johor Bahru.

\section{Results}

\section{1) Influence of HEC on the knowledge, attitude, and practice of healthy living among medical students}

From the interviews, the judges gave the students mean ratings of 4.0/5 (range 3.5 - 4.9, Table 1).

We also analyzed the responses of the students themselves as they commented on their learning, and on the program. Altogether, we received 77 out of a total of 127 questionnaires (response rate: 60.6\%) from the Year 3 medical students. In contrast to the high scores awarded by the judges, students themselves were less certain if their knowledge, attitudes, and practice had improved from the program. Only about half of students (49\% - 
Table 1. Judges' scores on the five themes.

\begin{tabular}{ccccccccc}
\hline \multirow{2}{*}{$\begin{array}{c}\text { Group } \\
\text { theme }\end{array}$} & \multicolumn{2}{c}{ Score } & \multicolumn{3}{c}{ p values $^{\mathrm{a}}$} & & \\
\cline { 2 - 9 } & Mean & SD & Lon & Spi & Exe & Nut & Str \\
\hline Lon & 4.9 & 0.3 & $\mathrm{x}$ & 0.000 & 0.000 & 0.000 & 0.000 \\
Spi & 3.6 & 0.5 & 0.000 & $\mathrm{x}$ & 0.3 & 0.0013 & 0.14 \\
Exe & 3.5 & 1 & 0.000 & 0.3 & $\mathrm{x}$ & 0.012 & 0.12 \\
Nut & 4.1 & 0.2 & 0.000 & 0.0013 & 0.012 & $\mathrm{x}$ & 0.049 \\
Str & 3.8 & 0.5 & 0.000 & 0.14 & 0.12 & 0.049 & $\mathrm{x}$ \\
\hline
\end{tabular}

Lon: Longevity; Spi: Spirituality; Exe: Exercise as medicine; Nut: Nutrition; Str: Stress and sleep. ${ }^{\text {a}}$ The right hand side of the table compares the performance of the different groups with each other. Values represent a calculation of p value, using an unpaired, one-tailed t-test. Thus, comparing the results of the "Exercise" theme with the "Spirituality" theme, the p value was 0.3 .

56\%) stated that they were satisfied or totally satisfied, and that their knowledge, attitudes, and practice had shown clear improvements (Table 2).

A Spearman's correlation matrix was prepared for these responses. There were large and positive correlations between all five variables. In terms of satisfaction with the HEP, the correlation coefficients between the question "Overall, how satisfied are you with the HEP?" and all other items ranged from 0.64 to 0.782 . Correlations between knowledge of healthy living, attitude towards healthy living, and practice of healthy living were large, exceeding 0.8 .

In providing feedback on the program as a whole, over two-thirds (60\% - 71\%) of students stated that they felt they had achieved "a lot" or "almost all” of the learning objectives of the program (Table 3).

A Spearman's correlation matrix was prepared for these responses. There were large and positive correlations between all variables. In terms of achievement of the learning objectives, the correlation coefficients between the five items ranged from 0.47 to 0.71 , suggesting moderate to large positive correlations.

\section{2) Learning experiences of the students during the HEC}

Commenting on the community-based learning experience, students agreed (66\% - 86\%) that the Health Enhancement Program provided a preferred learning environment in many ways (Table 4).

A Spearman's correlation matrix of the 12 items in the learning style questionnaire of the HEP showed medium to large and positive correlations between all twelve variables based on the following criteria as suggested by Cohen [16]: $r=0.10-0.29$ (small correlation), $r=0.30-0.49$ (medium correlation), and $r=0.50-1.0$ (large correlation). In particular, the last item (Q12) that poses the inquiry of whether the HEP was a success, the correlation coefficients between Q12 and all other items (Q1 - Q11) range from 0.608 to 0.783 (Table 5).

\section{Discussion}

Community engagement provides students and staff the opportunity to observe and learn local customs and traditions. They learn to apply their knowledge and skills of health promotion and disease prevention within the community, and develop confidence in dealing with members of community.

In order to define health issues within actual communities, the Clinical School Johor Bahru (CSJB) decided to innovate and provide real life experiences to supplement the theory of the HEP for year 3 students. This idea led to the creation of the Health Enhancement Carnival (HEC) series, beginning from 2012.

The HEC is nested within the scope of the HEP. It provides perspective on key elements of HEP, and explores roles and reactions of participants, providers, students, and parents in promotion of healthy living.

The HEC also provides an opportunity to observe students' learning through teaching and strategic use of teaching-learning resources (learning suites) within the context of local community (community participation/ engagement). Combined with the initial (year 1 and 2) phases of the HEP, this program incorporates the principle of Blended Learning (BL) (hybrid, technology-mediated instruction, web-enhanced instruction, and mixedmode instruction) [17] [18].

In the current context, experiential or social learning of medicine in the community settings brings into focus the innovation and creativity that makes learning challenging, interesting and fun [2] [3]. The HEC provides an interesting opportunity to observe the strengths and weaknesses of learning in groups (collaborative learning) and the translation of theoretical knowledge into practical learning skills. Students learn through teaching and 
Table 2. Student perceptions of their own changes in knowledge, attitudes and practice. They answered the questions listed under the column “Questions” (the HEP Healthy Living Questionnaire) $(\mathrm{N}=77)$.

\begin{tabular}{|c|c|c|c|c|c|}
\hline Questions & $\begin{array}{l}\text { Not at all } \\
\text { satisfied/achieved }\end{array}$ & $\begin{array}{l}\text { Not achieved/ } \\
\text { improved }\end{array}$ & Neutral & $\begin{array}{l}\text { Achieved/ } \\
\text { improved }\end{array}$ & $\begin{array}{c}\text { Totally } \\
\text { satisfied/ } \\
\text { achieved }\end{array}$ \\
\hline Overall, how satisfied are you with the HEP? & 13 & 6.5 & 31.2 & 35 & 14.3 \\
\hline $\begin{array}{l}\text { Overall, are the learning objectives of the HEP } \\
\text { achieved? }\end{array}$ & 9.1 & 10.4 & 27.3 & 31.1 & 22.1 \\
\hline $\begin{array}{l}\text { Overall, has the HEP improved your knowledge } \\
\text { about healthy living? }\end{array}$ & 15.6 & 6.5 & 24.7 & 32.4 & 20.8 \\
\hline $\begin{array}{l}\text { Overall, has the HEP improved your attitude } \\
\text { about healthy living? }\end{array}$ & 10.4 & 14.3 & 20.8 & 33.7 & 20.8 \\
\hline $\begin{array}{l}\text { Overall, has the HEP improved your practice } \\
\text { about healthy living? }\end{array}$ & 11.7 & 10.4 & 22.1 & 35 & 20.8 \\
\hline
\end{tabular}

Table 3. Student feedback on the program as a whole. They answered the following question: "To what extent have you succeeded in achieving the learning objectives of HEP?” ( $\mathrm{N}=77)$.

\begin{tabular}{lccccc}
\hline & Almost none & A little & Some & A lot & Almost all \\
\hline Longevity & 1.3 & 9.1 & 27.3 & 41.5 & 20.8 \\
$\begin{array}{l}\text { Managing workplace stress and strategies to enhance } \\
\text { sleep }\end{array}$ & 2.6 & 5.8 & 26.7 & 51.3 & 13.6 \\
Exercise as medicine & 1.4 & 2.7 & 35.6 & 38.4 & 21.9 \\
Food as medicine & 2.6 & 3.9 & 22.1 & 44.1 & 27.3 \\
Spirituality and health & 1.3 & 6.6 & 25 & 55.3 & 11.8 \\
\hline
\end{tabular}

Table 4. Student responses on the teaching-learning method: the HEP Learning Style Questionnaire. Students responded to the questions asked in the column "Questions” $(\mathrm{N}=77)$.

\begin{tabular}{|c|c|c|c|c|c|}
\hline Questions & $\begin{array}{l}\text { Strongly } \\
\text { disagree }\end{array}$ & Disagree & Neutral & Agree & $\begin{array}{l}\text { Strongly } \\
\text { agree }\end{array}$ \\
\hline Health enhancement encourages a collegial atmosphere & 1.3 & 2.6 & 14.3 & 59.7 & 22.1 \\
\hline $\begin{array}{l}\text { HEP provides a safe and nonjudgmental environment for students } \\
\text { to discuss their views and opinions }\end{array}$ & 2.6 & 2.6 & 18.1 & 50.7 & 26 \\
\hline HEP encourages students to participate in community education & 0.0 & 2.6 & 11.7 & 54.5 & 31.2 \\
\hline HEP encourages students to assume leadership responsibilities & 1.3 & 2.6 & 18.1 & 46.8 & 31.2 \\
\hline $\begin{array}{l}\text { HEP encourages students to interact with the community to } \\
\text { spread the message of healthy living and wellbeing }\end{array}$ & 1.3 & 2.6 & 14.3 & 48 & 33.8 \\
\hline HEP ensures that students participate in the sessions & 0.0 & 3.9 & 17.1 & 47.4 & 31.6 \\
\hline $\begin{array}{l}\text { HEP keeps students focused on the topic without imposing or } \\
\text { being directive }\end{array}$ & 3.9 & 5.2 & 22.1 & 42.8 & 26 \\
\hline $\begin{array}{l}\text { HEP encourages students to take responsibility for identifying } \\
\text { their learning objectives }\end{array}$ & 2.6 & 3.9 & 15.6 & 53.2 & 24.7 \\
\hline HEP encourages post-session self-directed learning & 2.6 & 6.5 & 24.7 & 44.1 & 22.1 \\
\hline $\begin{array}{l}\text { HEP provides prompt feedback regarding students' performance } \\
\text { and contribution }\end{array}$ & 0.0 & 12 & 20 & 41.3 & 26.7 \\
\hline $\begin{array}{l}\text { HEP provides students with an innovative and unique experience } \\
\text { in learning a module outside the usual classroom setting }\end{array}$ & 3.9 & 6.5 & 14.3 & 42.8 & 32.5 \\
\hline $\begin{array}{l}\text { Taking all aspects into consideration, the Health Enhancement } \\
\text { Program was a success }\end{array}$ & 2.6 & 4 & 21.1 & 44.7 & 27.6 \\
\hline
\end{tabular}


Table 5. The Spearman rho correlation matrix of the 12 items in the Learning Style Questionnaire (see Table 4). For all values listed, the 2-tailed $\mathrm{p}<0.001 ; \mathrm{n}=77(\mathrm{~N}=77)$.

\begin{tabular}{|c|c|c|c|c|c|c|c|c|c|c|c|}
\hline Q1 & Q1 & Q2 & Q3 & Q4 & Q5 & Q6 & Q7 & Q8 & Q9 & Q10 & Q11 \\
\hline Q2 & 0.705 & & & & & & & & & & \\
\hline Q3 & 0.677 & 0.570 & & & & & & & & & \\
\hline Q4 & 0.599 & 0.607 & 0.717 & & & & & & & & \\
\hline Q5 & 0.694 & 0.667 & 0.737 & 0.710 & & & & & & & \\
\hline Q6 & 0.417 & 0.463 & 0.597 & 0.480 & 0.629 & & & & & & \\
\hline Q7 & 0.522 & 0.607 & 0.597 & 0.597 & 0.589 & 0.602 & & & & & \\
\hline Q8 & 0.599 & 0.617 & 0.666 & 0.666 & 0.658 & 0.395 & 0.679 & & & & \\
\hline Q9 & 0.620 & 0.645 & 0.533 & 0.533 & 0.581 & 0.421 & 0.721 & 0.745 & & & \\
\hline Q10 & 0.458 & 0.547 & 0.493 & 0.493 & 0.503 & 0.635 & 0.568 & 0.556 & 0.619 & & \\
\hline Q11 & 0.654 & 0.632 & 0.565 & 0.565 & 0.690 & 0.481 & 0.598 & 0.640 & 0.671 & 0.579 & \\
\hline Q12 & 0.671 & 0.735 & 0.655 & 0.655 & 0.783 & 0.608 & 0.688 & 0.664 & 0.734 & 0.609 & 0.716 \\
\hline
\end{tabular}

application of healthy lifestyle principles to a younger audience (secondary school students). As a form of reflexive learning this has bearing upon their own health and well-being [13] [19].

The HEC also provides learning through competition in that students were divided into five groups, with each group charged with preparing a challenging health enhancement presentation during the carnival that will be judged and rewarded.

An important aspect of undergraduate medical education is the emphasis for health promotion and disease prevention (primary prevention) in order to prepare and nurture aspiring young doctors towards embracing a truly healthy lifestyle.

In this project, we have generally assumed that medical students possess superior knowledge (K), attitudes (A), and practices (P) about health promotion, disease prevention, and healthy lifestyles compared to students from other disciplines. We examined the evidence for the KAP of healthy living using themes derived from ESSENCE [1]: workplace stress and sleep enhancement, exercise as medicine, food as medicine, longevity and ageing, and spirituality and health.

1) Healthy Living: Knowledge, Attitude, and Practice (KAP)

The judges' evaluated the students' booths, posters, audiovisual aids, and communication skills. They checked these media against the required learning outcomes, and further quizzed the students with reference to the program objectives. The high marks awarded indicate that this innovative teaching-learning method is effective, though in this protocol we did not specifically make comparisons with performances of students from previous years.

Interestingly, students working on the themes of longevity and nutrition were judged significantly better than those working on the themes of spirituality and health, exercise as medicine, and managing workplace stress and strategies to enhance sleep. The difference might indicate more motivated students; alternatively the difference could be an indication that the high-scoring theme is one that lends itself to better learning. Future experience will show if the longevity and nutrition themes are actually easier to learn in this setting.

With reference to the students' own responses in the questionnaires, most students scored "satisfied/totally satisfied", "achieved/totally achieved", or "improved/totally improved" to the 5 questions (range: $49.35 \%$ to 55.84\%) (Table 2). The fact that there is a sizeable proportion of respondents who responded negatively or neutrally indicates that there were elements in the HEP that may require further attention following a constructive evaluation. The questions cover the following: 1) satisfaction with the HEP, 2) achievement of the learning objectives of the HEP, 3) whether the HEP improves the student's knowledge of healthy living, 4) whether the HEP improves the student's attitude of healthy living, and 5) whether the HEP improves the student's practice of healthy living.

Analyzing student responses towards healthy living (Table 2), we noted that the correlation coefficients between the knowledge of healthy living, attitude towards healthy living, and practice of healthy living exceeded 0.8. What this means is that there is a strong correlation between knowledge, attitude and practice of healthy 
living that other studies [20] have not been able to demonstrate. We find this exciting because it means that the HEP in Monash University Malaysia has succeeded in translating knowledge about healthy living into effective attitudinal and behavioral change among our medical students. Hopefully, this change will also translate into stronger advocacy about healthy living when these students become doctors and specialists in the near future [21] [22].

\section{2) Learning experiences of the students during the HEC}

Overall, the majority of students agreed or strongly agreed to the twelve questions (range: $66.24 \%$ to $85.72 \%$ ) (Table 4). The result is an affirmation of the success of the HEP in providing a unique learning environment within the community, using a strong, collaborative and participatory approach [7] [8] [23].

The matrix (Table 5) shows large positive correlation coefficients ( $r=0.608$ to 0.783 ). Q12 will increase with any increase in any of the other items (Q1 - Q11). This is not surprising as all other items (Q1 - Q11) measure characteristics that are necessary for a successful community-based, blended learning program with a strong emphasis on professional attributes. The program promotes attitudes that are collegial, participatory, focus driven, self-directed, community-based, non-judgmental and innovative, and encourages leadership responsibility and teamwork [2] [3] [6].

\section{Conclusion and Recommendations}

In conclusion, the Health Enhancement Program (HEP) has been a highly successful program in terms of its innovativeness in creating the Health Enhancement Carnival (HEC) that has enabled students to learn about healthy living within the context of the local community. More importantly, the HEP has allowed students to be creative, using all available resources of blended learning to achieve its learning objectives. The HEP and HEC empower students to learn according to their optimal learning styles and to unleash their hidden creativity, leadership abilities, and the capacity to learn through teaching. Despite a few issues, the HEP is deemed highly successful based on the formal and informal feedbacks from students, teachers and students in the participating school.

\section{Practice Points}

* That the HEP through its HEC to be sustained across different school environments so as to enable different cohorts of medical student's unique opportunities to learn through different communities;

* That the Healthy Brigades created through the HEC empowered to be part of the Jeffrey Cheah School of Medicine and Health Sciences as brand ambassadors of our medical school;

* That medical education research created within the HEP and HEC to allow for continuing research into learning styles of medical students that will add to the enrichment of our medical curriculum.

\section{References}

[1] Hassed, C. (2008) The Essence of Health: The Seven Pillars of Wellbeing. Random House, Sydney.

[2] DiBartola, L.M. (2006) The Learning Style Inventory Challenge: Teaching about Teaching by Learning about Learning. Journal of Allied Health, 35, 238-245.

[3] DiLullo, C., McGee, P. and Kriebel, R.M. (2011) Demystifying the Millennial Student: A Reassessment in Measures of Character and Engagement in Professional Education. Anatomical Sciences Education, 4, 214-226. http://dx.doi.org/10.1002/ase.240

[4] Goodie, J.L., Williams, P.M., Kurzweil, D. and Marcellas, K.B. (2011) Can Blended Classroom and Distributed Learning Approaches Be Used to Teach Medical Students How to Initiate Behavior Change Counseling During a Clinical Clerkship? Journal of Clinical and Psychological Medicine Settings, 18, 353-360. http://dx.doi.org/10.1007/s10880-011-9261-4

[5] Eme'lianova, G.F., Pavlov, V.A. and Patoka, G.A. (1989) Increasing the Effectiveness of Training of Medical Students in Promoting the Knowledge of Medicine and Hygiene (in Russia). Sovetskoe Zdravookhranenie, 10, 63-64. [English Abstract]

[6] Davidson, L.K. (2009) Educational Innovation in an Undergraduate Medical Course: Implementation of a Blended E-Learning, Team-Based Learning Model. Unpublished Master of Education Thesis, Queen’s University Kingston, Ontario, Canada.

[7] Averill, N.J., Sallee, J.M., Robinson, J.T., McFarlin, J.M., Montgomery, A.A., Burkhardt, G.A., Schulz-Burton, M.D. 
and Elam, C.L. (2007) A First-Year Community-Based Service Learning Elective: Design, Implementation, and Reflection. Teaching \& Learning in Medicine, 19, 47-54. http://dx.doi.org/10.1080/10401330709336623

[8] Chastonay, P., Zesiger, V., Klohn, A., Soguel, L., Mpinga, E.K., Vu, N. and Bernheim, L. (2013) Development and Evaluation of a Community Immersion Program During Preclinical Medical Studies: A 15-Year Experience at the University of Geneva Medical School. Advances in Medical Education Practice, 22, 69-76. http://dx.doi.org/10.2147/AMEP.S41090

[9] Ní Chróinín, D., Kyne, L., Duggan, J., Last, J., Molphy, A., O’Shea, D., Steele, M., Bury, G. and Cullen, W. (2012) Medicine in the Community: A Unique Partnership. Clinical Teacher, 9, 158-163. http://dx.doi.org/10.1111/j.1743-498X.2012.00527.x

[10] Marcus, M.T., Taylor, W.C., Hormann, M.D., Walker, T. and Carroll, D. (2011) Linking Service-Learning with Community-Based Participatory Research: An Interprofessional Course for Health Professional Students. Nursing Outlook, 59, 47-54. http://dx.doi.org/10.1016/j.outlook.2010.10.001

[11] Saylor, C.D., Keselyak, N.T., Simmer-Beck, M. and Tira, D. (2011) Evaluation of Social Interaction, Task Management, and Trust among Dental Hygiene Students in a Collaborative Learning Environment. Journal of Dental Education, 75, 180-189.

[12] Youngblood, N. and Beitz, J.M. (2001) Developing Critical Thinking with Active Learning Strategies. Nurse Educator, 26, 39-42. http://dx.doi.org/10.1097/00006223-200101000-00016

[13] Claudio, G.C. (2005) Learning through Teaching. Management Learning, 36, 87-115.

[14] Strasser, R.P. (2010) Community Engagement: A Key to Successful Rural Clinical Education. Rural and Remote Health, 10, 1543.

[15] Karamizadeh, Z., Zarifsanayei, N., Faghihi, A.A., Mohammadi, H. and Habibi, M. (2012) The Study of Effectiveness of Blended Learning Approach for Medical Training Courses. Iranian Red Crescent Medical Journal, 14, 41-44.

[16] Cohen, J. (1988) Statistical Power Analysis for the Behavioral Sciences. 2nd Edition, Lawrence Erlbaum Associates, New Jersey.

[17] Martyn, M. (2003) The Hybrid Online Model: Good Practice. Educause Quarterly, 26, 18-23.

[18] Staker, H. and Horn, M.B. (2012) Classifying K-12 Blended Learning. Innosight Institute, 1-17.

[19] Haq, C., Steele, D.J., Marchand, L., Seibert, C. and Brody, D. (2004) Integrating the Art and Science of Medical Practice: Innovations in Teaching Medical Communication Skills. Family Medicine, 36, S43-S50.

[20] Sajwani, R.A., Shoukat, S., Raza, R., Shiekh, M.M., Rashid, Q., Siddique, M.S., Panju, S., Raza, H., Chaudhry, S. and Kadir, M. (2009) Knowledge and Practice of Healthy Lifestyle and Dietary Habits in Medical and Non-Medical Students of Karachi, Pakistan. Journal of the Pakistan Medical Association, 59, 650-655.

[21] Delnevo, C.D., Abatemarco, D.J. and Gotsch, A.R. (1996) Health Behaviors and Health Promotion/Disease Prevention Perceptions of Medical Students. American Journal of Preventive Medicine, 12, 38-43.

[22] Holtz, K.A., Kokotilo, K.J., Fitzgerald, B.E. and Erica Frank, E. (2013) Exercise Behaviour and Attitudes among Fourth-Year Medical Students at the University of British Columbia. Canadian Family Physician, 59, e26-e32.

[23] Meah, Y.S., Smith, E.L. and Thomas, D.C. (2009) Student-Run Medical Clinics: Novel Arena to Educate Medical Students on System Based Practice. Mount Sinai Journal of Medicine, 76, 344-356. http://dx.doi.org/10.1002/msj.20128 
Scientific Research Publishing (SCIRP) is one of the largest Open Access journal publishers. It is currently publishing more than 200 open access, online, peer-reviewed journals covering a wide range of academic disciplines. SCIRP serves the worldwide academic communities and contributes to the progress and application of science with its publication.

Other selected journals from SCIRP are listed as below. Submit your manuscript to us via either submit@scirp.org or Online Submission Portal.
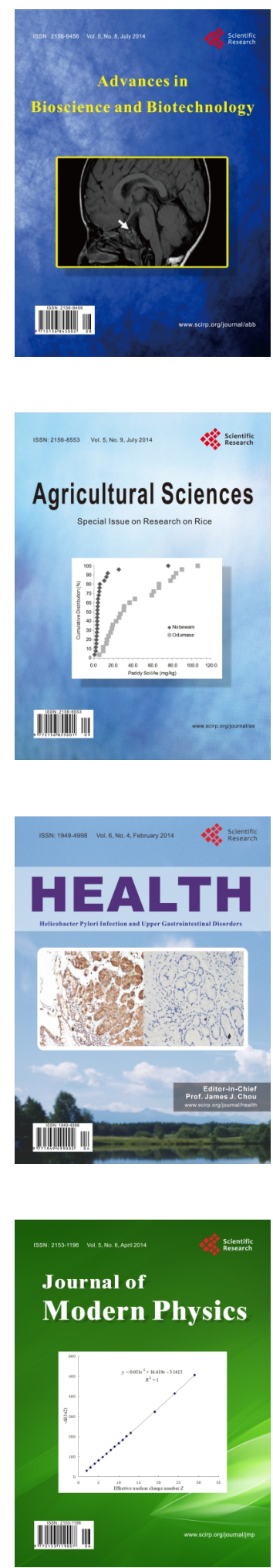
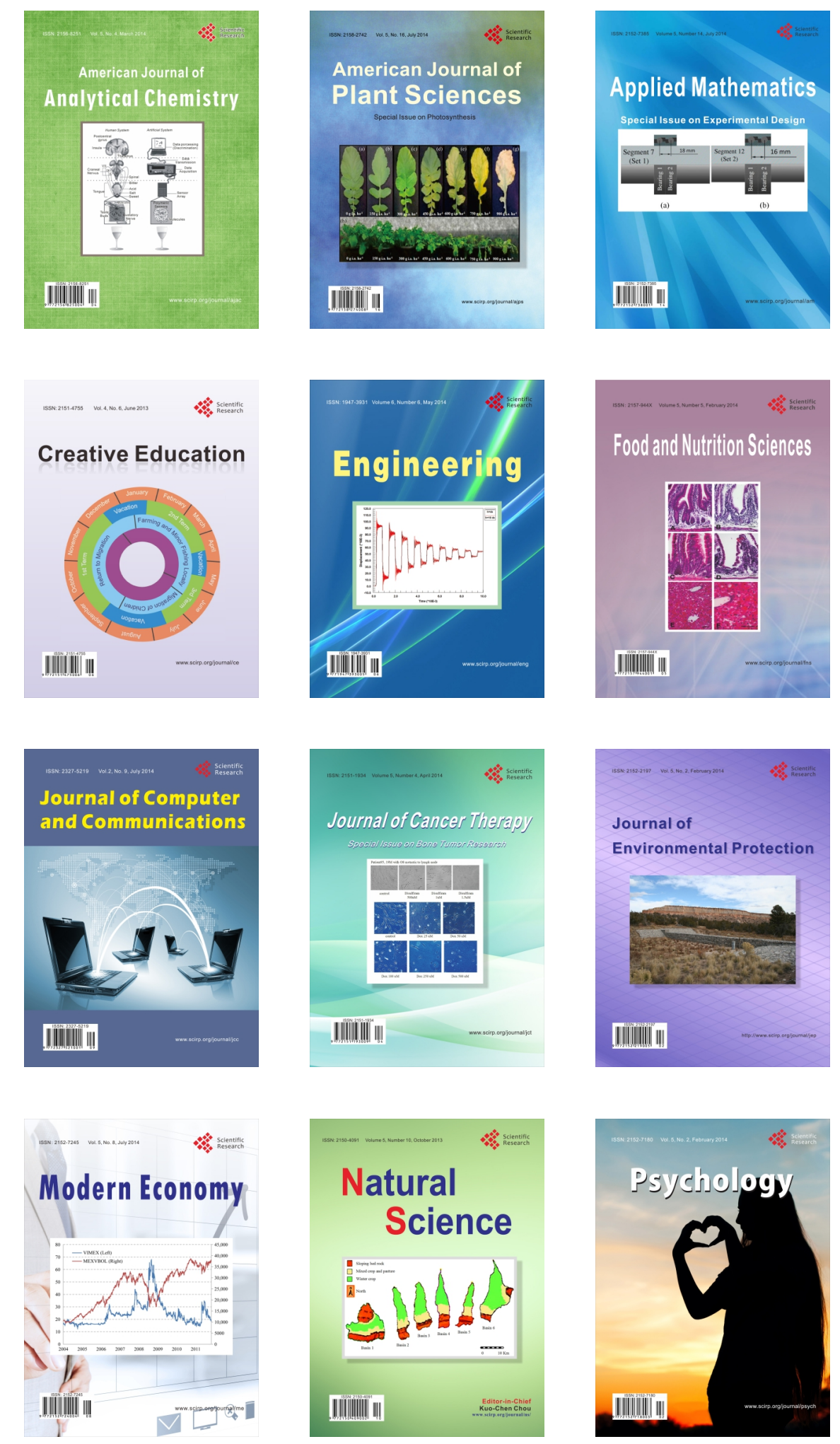